\title{
ANÁLISE GEOESTATÍSTICA PARA A ESTIMATIVA DA SUPERFÍCIE DE PRECIPITAÇÃO EM MINAS GERAIS
}

André Luiz Profeta ${ }^{1}$

\section{Resumo}

O presente trabalho se propõe a avaliar a aplicação da geoestatística por meio da krigagem ordinária e cokrigagem, buscando identificar qual desses métodos oferece melhor resultado para a estimação da superfície de precipitação pluvial para o estado de Minas Gerais. As séries históricas de precipitação utilizadas correspondem ao período de 2005 a 2014, de 59 estações climatológicas, 43 do Instituto Nacional de Meteorologia (INMET) e 16 da Agência Nacional de Águas (ANA). No caso da cokrigagem, a variável secundária considerada foi a altitude, estimada a partir de um modelo digital do terreno. A análise exploratória dos dados permitiu a definição de parâmetros para o ajuste dos modelos, principalmente por meio da análise do semivariograma, da verificação de tendência e de anisotropia. Foi identificada uma autocorrelação forte da precipitação, o que favoreceu o bom ajuste dos modelos, que foram avaliados pela validação cruzada. A krigagem ordinária apresentou melhores resultados para a média anual e a média da estação seca, enquanto a cokrigagem apresentou melhor resultado para a estação chuvosa, concordando com a análise de correlação entre as variáveis que se mostrou mais forte apenas para esse período.

Palavras chave:Precipitação, Geoestatística, Altitude, Autocorrelação

\begin{abstract}
This study aims to evaluate the application of geostatistics by ordinary kriging and cokriging in order to identify which of these methods provides better results for the estimation of rainfall surface for the Minas Gerais state. The rainfall time series used correspond to the period from 2005 to 2014, from 59 weather stations, 43 of the INMET (National Institute of Meteorology) and 16 of the ANA (National Agency of Water). In the case of cokriging, the altitude was considered a secondary variable, estimated from a digital terrain model. The exploratory data analysis allowed the definition of parameters for the adjustment of the models, mainly through the semivariogram analysis, of the tendency analysis and anisotropy. A strong autocorrelation precipitation was identified, which favoured the good fit of the models, which were evaluated by cross-validation. The ordinary kriging shows better results for the annual average and the average of the dry season, while cokriging shows better results for the rainy season, agreeing with the analysis of the correlation between the variables that proved to be stronger only for that period.
\end{abstract}

Keywords:Precipitation, Geostatistics, Altitude, Autocorrelation

\footnotetext{
1 (Universidade Federal de Minas Gerais - UFMG/IGC - Programa de Pós Graduação em Análise e Modelagem de Sistemas Ambientais) andreluiz.geo@gmail.com
} 


\section{1- INTRODUÇÃO}

A precipitação apresenta uma variabilidade espacial que está associada a diversos elementos naturais, como circulação atmosférica, latitude e relevo (NUNES et al., 2009). O estudo de sua distribuição no espaço permite uma melhor compreensão do ciclo hidrológico e, dessa forma, pode ser aplicado em diversas demandas da sociedade, como o planejamento agrícola, o planejamento da infraestrutura urbana e da distribuição de água, bem como o reconhecimento das áreas de maior concentração de chuvas e das épocas de sua ocorrência, o que subsidia a identificação de áreas de risco, áreas de recarga do lençol freático etc.

A literatura oferece diferentes métodos para a estimação de uma superfície de precipitação. Há os métodos determinísticos que utilizam apenas fórmulas matemáticas e princípios geométricos, como o método do Inverso do Quadrado da Distância (IQD); e os métodos estocásticos que se fundamentam, além da matemática, na teoria estatística, caso da regressão linear e da geoestatística (CASTRO et al., 2014; YAMAMOTO; LANDIM, 2013). A vantagem desses sobre aqueles é a possibilidade de se ter uma estimação da incerteza para a variável interpolada, o que não é possível utilizando métodos determinísticos (YAMAMOTO; LANDIM, 2013).

O método geoestatístico se fundamenta na teoria das variáveis regionalizadas, proposta por Georges Matheron na década de 60, na qual a distribuição de uma variável no espaço depende de sua localização, com um componente aleatório e um estrutural que reflete a dependência espacial (YAMAMOTO e LANDIM, 2013). Ao se explorar esse conceito é possível otimizar a superfície interpolada pela atribuição de pesos que considera não apenas a distância entre as amostras como forma de ponderação (caráter determinístico), mas também leva em conta a sua distribuição e variabilidade (caráter estocástico), elementos que podem ser analisados por meio do semivariograma (YAMAMOTO e LANDIM, 2013; ANDRIOTTI, 2003).

A aplicação da geoestatística como método interpolador para precipitação tem sido usada com sucesso em diversos trabalhos (CUNHA et al., 2013; CARVALHO e ASSAD, 2003; GOOVAERTS, 2000). Considerando a correlação da precipitação com outras variáveis, tem-se também aplicado a cokrigagem, principalmente utilizando a altitude como variável secundária (CASTRO et al., 2014; GOOVAERTS, 2000). A variável secundária, com maior número de amostragem, é utilizada com o objetivo de melhorar a estimativa da variável primária, com amostragem reduzida (YAMAMOTO; LANDIM, 2013). Segundo Nunes et al. (2009), o relevo é um fator importante para o entendimento da variabilidade climática em todo o sudeste brasileiro.

Dessa forma, esse trabalho se se propõe a avaliar a aplicação da geoestatística por meio da krigagem ordinária e cokrigagem, buscando identificar qual desses métodos oferece melhor 
resultado para a estimação da superfície de precipitação para o estado de Minas Gerais, considerando três períodos de análise: média anual, média da estação chuvosa e média da estação seca, para um intervalo temporal de 10 anos (2005 - 2014). Para a cokrigagem, a variável secundária utilizada foi a altitude.

\section{2- ÁREA DE ESTUDO}

Minas Gerais integra a região sudeste do Brasil, a qual se caracteriza pela alta densidade demográfica e pelo destaque no cenário econômico do país. Essa região possui grande diversidade geomorfológica, climática e uma rica biodiversidade. A precipitação tem distribuição espacial com variações significativas ao longo de toda a extensão territorial da região, e uma distribuição temporal com duas estações bem definidas, a chuvosa, de outubro a março, e a seca, de abril a setembro (NUNES et al., 2009).

Os padrões climáticos do sudeste brasileiro são definidos em grande e mesoescala pela circulação superior da atmosfera, com interferência dos fenômenos também de grande escala, como o El Niño e La Niña. Numa escala local, as variações desses padrões podem ser influenciadas por aspectos do relevo, orientação das vertentes, uso do solo, entre outros fatores (NUNES et al., 2009).

A configuração morfológica de Minas Gerais é decorrente de uma expressiva atividade tectônica ao longo do tempo geológico associado às ações de ordem climáticas sobre os diferentes tipos litológicos, bem como seus aspectos estruturais (SAADI, 1991). As principais elevações do estado são representadas pela Serra da Mantiqueira, Serra da Canastra e Serra do Espinhaço.

\section{3- MATERIAIS E MÉTODOS}

Para a execução desse trabalho, os processamentos foram realizados no software ArcGIS® 9.3, considerados duas variáveis:

- amostragem de pluviometria do estado de Minas Gerais, como variável primária;

- modelo digital de terreno - MDT, como variável secundária.

A parte inicial do estudo foi o levantamento e tratamento dos dados de pluviometria e altimetria. Para a pluviometria foram consideradas inicialmente as 48 estações convencionais do Instituto Nacional de Meteorologia (INMET), a partir dos dados históricos do Banco de Dados Meteorológicos para Ensino e Pesquisa (BDMEP). A escala temporal de análise adotada foi de 10 anos, período de 2005 a 2014. Após a organização e análise dos dados, optou-se por descartar cinco estações devido à inexistência de dados em um ou mais anos no período de análise. Para 
compensar a retirada desses dados, bem como para obter amostragem para extensas áreas sem dados no estado, foram acrescentas mais 16 estações do sistema de informações hidrológicas HidroWeb da base de dados da Agência Nacional de Águas (ANA), totalizando 59 estações. Dentre as estações incluídas, do total de 7080 registros de dados, considerando a pluviometria mensal para o período de 10 anos, faltaram apenas 40 registros. Assim, tendo-se em vista que o dado de interesse foi a média mensal, ao se fazer o cálculo para os meses com ausência de dados em algum(s) ano(s), dividiu-se o total mensal pelo número de registros existentes. As estações pluviométricas se encontram amostradas de forma irregular no espaço (Figura 1A)

O MDT foi adquirido do site Brasil em Relevo, disponibilizado pela Empresa Brasileira de Pesquisa Agropecuária (EMBRAPA) e reamostrado para uma resolução espacial pior, de 10.000 metros (sua resolução original é de 90 metros - Figura 1B), com o objetivo de se obter valores de altitude representativos de uma área maior (Figura 1C). Transformou-se esse dado para o modelo vetorial (formato shapefile) do tipo polígono e, posteriormente, os polígonos em pontos. Dessa forma, obteve-se apenas um ponto para cada pixel ou um conjunto de pixels de mesmo valor. Seguindo as recomendações apresentadas por Yamamoto e Landim (2013) para casos de coestimativas, inclui-se a altitude correspondente à localização das estações, para garantir a heterotopia parcial das variáveis, quando há pontos amostrados de ambas as variáveis que são coincidentes (Figura 1D). Em casos de ausência desse dado, o mesmo foi estimado a partir do MDT original (90 metros).

Na segunda fase do estudo, foi realizada a exploração dos dados, conforme apresentado a seguir:

- verificação da necessidade de transformação dos dados utilizando o histograma de frequência, visando aproximá-los de uma distribuição normal, a qual oferece melhores resultados para a estimativa (JOHNSTON et al., 2001);

- análise de autocorrelação da variável precipitação por meio do semivariograma experimental (YAMAMOTO e LANDIM, 2013;

JOHNSTON et al., 2001), e do índice de Moran (ANSELIN, 2005);

- análise da correlação entre a precipitação e a altitude, aplicando regressão linear simples (CANCHO, 2004);

- análise de tendência e de anisotropia (YAMAMOTO e LANDIM, 2013; JOHNSTON et al., 2001). 


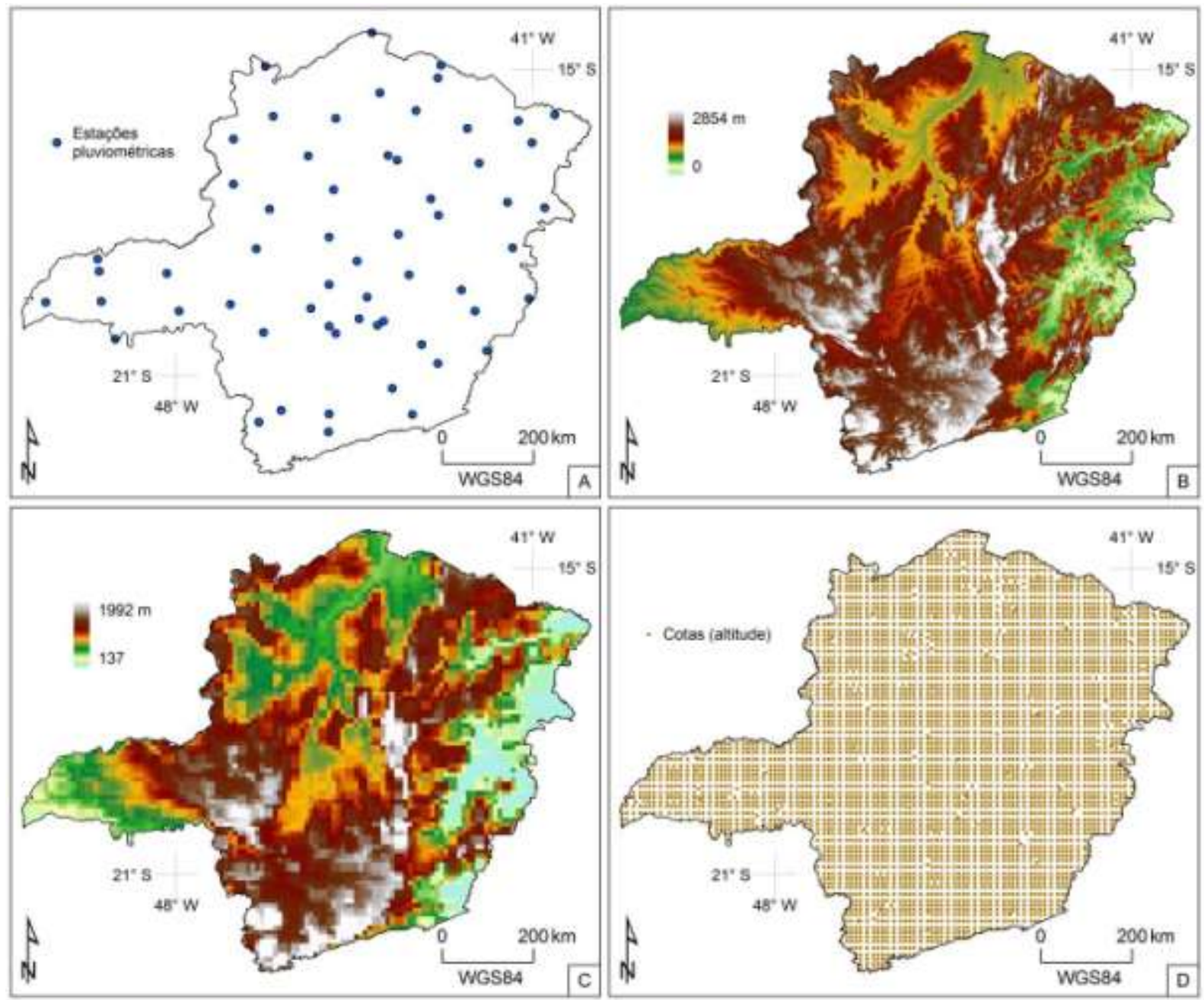

Figura 1: A) Localização das estações pluviométricas (INMET e ANA); B) Modelo digital de elevação com resolução de 90 metros; C) Modelo digital de elevação reamostrado para resolução espacial de 10.000 metros; D) Pontos de extração de altitude extraídos do MDT.

Após a análise exploratória dos dados, procedeu-se a execução da krigagem ordinária com a variável pluviometria e a cokrigagem considerando as variáveis pluviometria (variável primária) e altitude (variável secundária). Nesse passo deve-se escolher uma função matemática que melhor se ajusta ao semivariograma experimental, o que é feito de maneira interativa, testando-se diferentes parâmetros (ANDRIOTTI, 2002). Também é possível escolher o número de vizinhos a ser incluídos e o tipo de setor para especificar a geometria da área a ser considerada, visando um melhor ajuste do modelo (JOHNSTON et al., 2001).

A avaliação do melhor resultado foi feita com base na validação cruzada ao fim da execução do modelo. Nessa validação cada ponto de amostra de precipitação é omitido, um por vez, e é gerado um novo valor predito para esse ponto com base no modelo ajustado, permitindo assim um diagnóstico de acerto do modelo, por meio das estatísticas de erros fornecidas (JOHNSTON et al., 2001). Os erros utilizados para avaliação foram o erro médio padronizado e o erro médio quadrático padronizado (MOTA, 2008; ISAAKS e SRIVASTAVA, 1989). O erro 
médio padrão indica melhor ajuste quanto mais próximo de 0 e erro médio quadrático padronizado quanto mais próximo de 1 (JOHNSTON et al., 2001). Foram também construídos os mapas de erros de predição para a krigagem ordinária e cokrigagem, os quais permitem quantificar a incerteza para cada localização da superfície interpolada (JOHNSTON et al., 2001). É apresentada a discussão dos resultados em ambos os casos, com a indicação do melhor método dentre aqueles testados.

\section{4- RESULTADOS E DISCUSSÕES}

\subsection{Ajuste do modelo}

A análise exploratória dos dados auxiliou ao conhecimento mais aprofundado das variáveis, o que contribui na definição dos parâmetros para o ajuste do modelo. Em relação às análises realizadas, considerou-se:

- não aplicar nenhuma transformação dos dados, tendo em vista que a precipitação apresentou uma distribuição próxima de uma assimetria negativa e a altitude uma distribuição próxima da normal e, de acordo com Yamamoto e Landim (2013), nesses casos não é necessário a transformação;

- a análise do semivariograma mostrou a existência de forte autocorrelação da precipitação o que foi identificado também nos resultados do Índice de Moran (Tabela 1), justificando a aplicação da geoestatística;

- a cokrigagem foi aplicada, mas com a ressalva de que a correlação entre as variáveis foi fraca, principalmente para a estação seca (Figura 2);

- não consideração das tendências identificadas em ambas as variáveis, seguindo recomendações de Yamamoto e Landim (2013), que orientam a não remoção da tendência quando não se pode dizer com segurança as suas causas;

- a anisotropia foi identifica e considerada no modelo, tendo-se em conta que ela é analisada para a variável que se deseja estimar. Pela análise do modelo, a direção de anisotropia corresponde a um azimute de aproximadamente 300 graus para os três casos considerados: média mensal, média mensal da estação chuvosa e média mensal da estação seca. 
Tabela 1: Autocorrelação espacial da precipitação média anual, média da estação chuvosa e média da estação seca, no período de 2005 - 2014.

\begin{tabular}{l|c|c}
\hline $\begin{array}{c}\text { Precipitação média } \\
\mathbf{( 2 0 0 5} \mathbf{- 2 0 1 4 )}\end{array}$ & $\begin{array}{c}\text { Índice de } \\
\text { Moran }\end{array}$ & $\boldsymbol{Z}$ Score \\
\hline Anual & 0,75 & 7,95 \\
\hline Estação chuvosa & 0,78 & 8,22 \\
\hline Estação seca & 0,56 & 5,93 \\
\hline
\end{tabular}
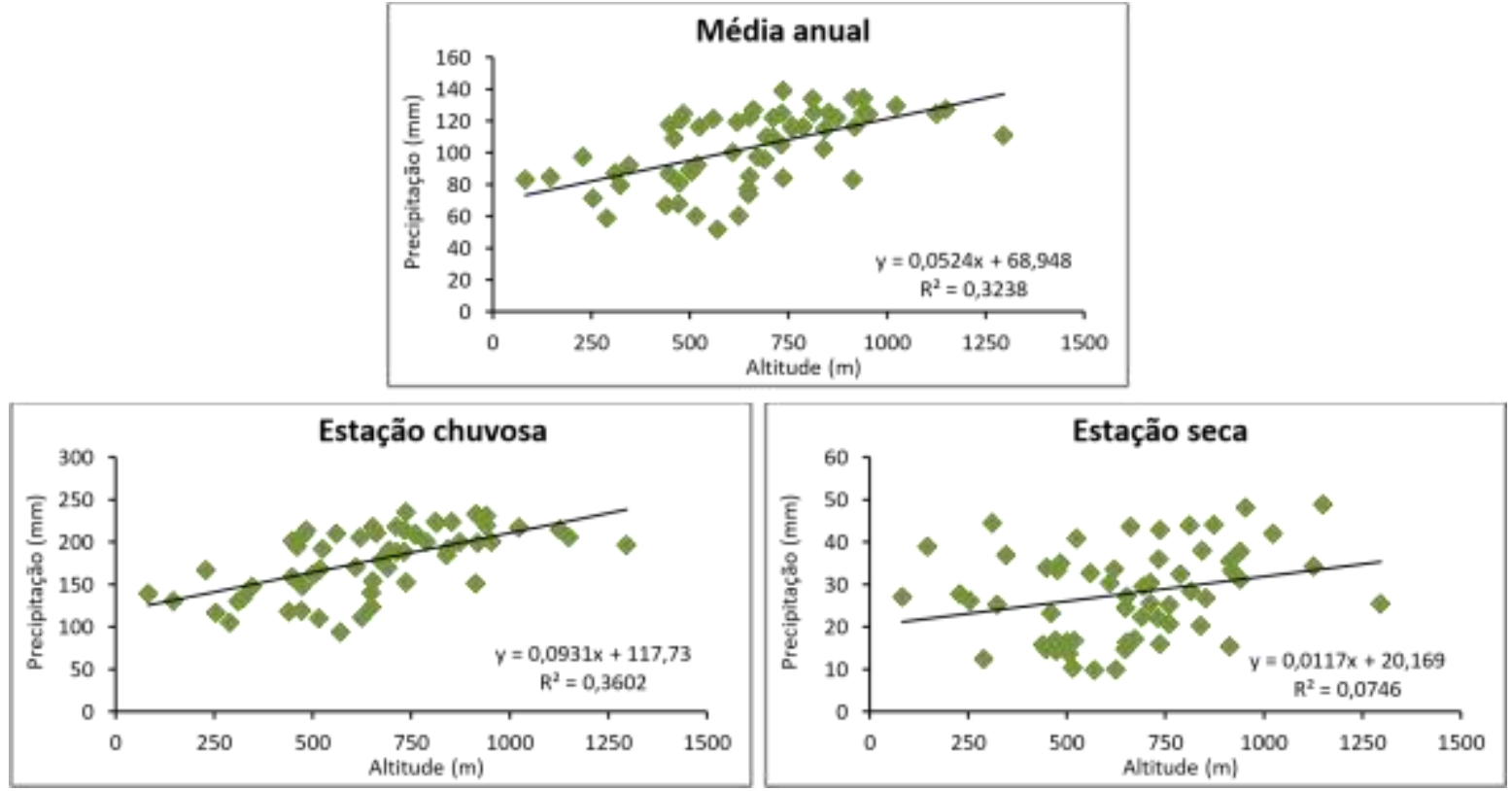

Figura 2: Regressão linear simples para a média anual, estação chuvosa e estação seca, com a precipitação como variável dependente e a altitude como variável independente.

Já em relação ao modelo o que apresentou melhores resultados foi o esférico. De acordo com Goovaerts (2000), esse modelo é amplamente utilizado e se caracteriza por apresentar um comportamento linear próximo à origem do semivariograma. As tabelas 2, 3 e 4 apresentam os parâmetros definidos para a krigagem ordinária e a cokrigagem.

Tabela 2: Parâmetros do modelo ajustado para a estimação da precipitação por krigagem ordinária.

\begin{tabular}{l|c|c|c|l|c}
\hline $\begin{array}{c}\text { Precipitação Média } \\
(\mathbf{2 0 0 5 - 2 0 1 4 )}\end{array}$ & Tendência & $\begin{array}{c}\text { Vizinhos } \\
\text { Incluídos }\end{array}$ & $\begin{array}{c}\text { Tipo de } \\
\text { Setor }\end{array}$ & Modelo & Anisotropia \\
\hline Anual & Não & 7 & $4 / 45^{\circ}$ & Esférico & Sim \\
\hline Estação chuvosa & Não & 7 & $4 / 45^{\circ}$ & Esférico & Sim \\
\hline Estação seca & Não & 5 & $4 / 45^{\circ}$ & Esférico & Sim \\
\hline
\end{tabular}

Tabela 3: Parâmetros do modelo ajustado para a estimação da precipitação por cokrigagem.

\begin{tabular}{l|c|c|c|c|c}
\hline $\begin{array}{c}\text { Precipitação Média } \\
\mathbf{( 2 0 0 5 - 2 0 1 4 )}\end{array}$ & Tendência & $\begin{array}{c}\text { Vizinhos } \\
\text { Incluídos }\end{array}$ & $\begin{array}{c}\text { Tipo de } \\
\text { Setor }\end{array}$ & Modelo & Anisotropia \\
\hline Anual & Não & 7 & $4 / 45^{\circ}$ & Esférico & Sim \\
\hline Estação chuvosa & Não & 7 & $4 / 45^{\circ}$ & Esférico & Sim \\
\hline Estação seca & Não & 7 & $4 / 45^{\circ}$ & Esférico & Sim \\
\hline
\end{tabular}


Tabela 4: Parâmetros do modelo ajustado para a estimação da precipitação por cokrigagem, considerando como variável secundária a altitude.

\begin{tabular}{c|c|c|c|c|c}
\hline $\begin{array}{c}\text { Variável } \\
\text { secundária }\end{array}$ & Tendência & $\begin{array}{c}\text { Vizinhos } \\
\text { Incluídos }\end{array}$ & $\begin{array}{c}\text { Tipo de } \\
\text { Setor }\end{array}$ & Modelo & Anisotropia \\
\hline Altitude & Não & 5 & $4 / 45^{\circ}$ & Esférico & Sim \\
\hline
\end{tabular}

\subsection{Krigagem versus cokrigagem}

A utilização do cokrigagem para a estimativa da precipitação, utilizando a altitude como segunda variável, mostrou resultados semelhantes aos obtidos pela krigagem ordinária. Os erros obtidos pela validação cruzada são apresentados na Tabela 5. Tanto os erros médios padronizados quanto os erros médios quadráticos padronizados mostram o bom ajuste dos modelos de estimação da precipitação. A julgar por esse último, pode-se dizer que:

- a krigagem apresentou melhor resultado para a média anual e para a média da estação seca;

- a cokrigagem apresentou resultado melhor para a média da estação chuvosa.

Esse resultado é compatível com a análise de regressão que indicou uma melhor correlação da altitude com a precipitação no período chuvoso. Avaliando as superfícies de precipitação geradas (Figuras 3 e 4) percebe-se que aquelas estimadas por cokrigagem apresentam curvas menos suavizadas em relação àquelas estimadas por krigagem ordinária. Uma diferença mais expressiva nesse sentido pode ser observada no mapa de precipitação da estação chuvosa (Figura 3B e 4B), principalmente ao sul do estado.

Tabela 5: Erros obtidos pela estimação da precipitação com krigagem e cokrigagem.

\begin{tabular}{l|l|c|c}
\hline & \multicolumn{1}{|c|}{$\begin{array}{c}\text { Análise de } \\
\text { Erros }\end{array}$} & $\begin{array}{c}\text { Erro Médio } \\
\text { Padronizado }\end{array}$ & $\begin{array}{c}\text { Erro Médio Quadrático } \\
\text { Padronizado }\end{array}$ \\
\hline \multirow{2}{*}{ Krigagem } & Anual & $-0,0001143$ & 1,025 \\
\cline { 2 - 4 } & Estação chuvosa & 0,0006207 & 0,9546 \\
\cline { 2 - 4 } & Estação seca & $-0,006561$ & 0,9959 \\
\hline \multirow{2}{*}{ Cokrigagem } & Anual & $-0,01753$ & 1,073 \\
\cline { 2 - 4 } & Estação chuvosa & $-0,01782$ & 1,001 \\
\cline { 2 - 4 } & Estação seca & $-0,01594$ & 0,971 \\
\hline
\end{tabular}

As superfícies de precipitação estimadas pelo método da krigagem ordinária (Figura 3) apresentam os padrões da distribuição espacial pluviométrica em Minas Gerais nos três períodos analisados. O mapa de precipitação de média anual (Figura 3A) apresenta uma distribuição bem próxima do mapa da estação chuvosa, porém, é evidente, com valores menores, já que a média anual inclui também os meses da estação seca que possuem menor índice pluviométrico. É possível perceber maior diferença entre o leste e sul do estado, o que é justificável ao se observar o mapa de precipitação estimado para a estação seca, que mostra maiores médias pluviométricas justamente nessas áreas. 
$\mathrm{Na}$ análise dos mapas de erros deve-se considerar que, assim como os mapas de estimativas de precipitação, a escala de cores possui correspondências em faixas diferentes para cada período considerado (média anual, média estação chuvosa e média estação seca). A princípio, todas as estimativas de erro possuem uma correspondência em sua distribuição no espaço, pois os três períodos considerados utilizam os mesmos pontos amostrais e os erros tendem a se concentrar onde há maior espaçamento de amostras, entretanto cabem algumas considerações:

- as duas últimas classes de erros ocupam uma área mínima (Figura 5) e estão localizadas principalmente no limite do estado, podendo ser decorrentes do efeito de borda, já que a amostragem corresponde apenas ao limite do estado;

- a estimativa para a estação chuvosa apresentou maiores erros quanto aos valores estimados, possivelmente devido a uma variabilidade maior do fenômeno nessa época (Figura 3E);

- a estação seca apresentou menores erros de estimativa (Figura 3F) e possui uma distribuição mais equitativa dos erros no espaço em relação á área, diferentemente dos outros dois períodos considerados, que apresentaram, na maior parte do estado, erros baixos a médios, considerando suas respectivas escalas de erros (Figura 5). Esse comportamento pode ser devido ao menor gradiente pluviométrico nessa estação. 

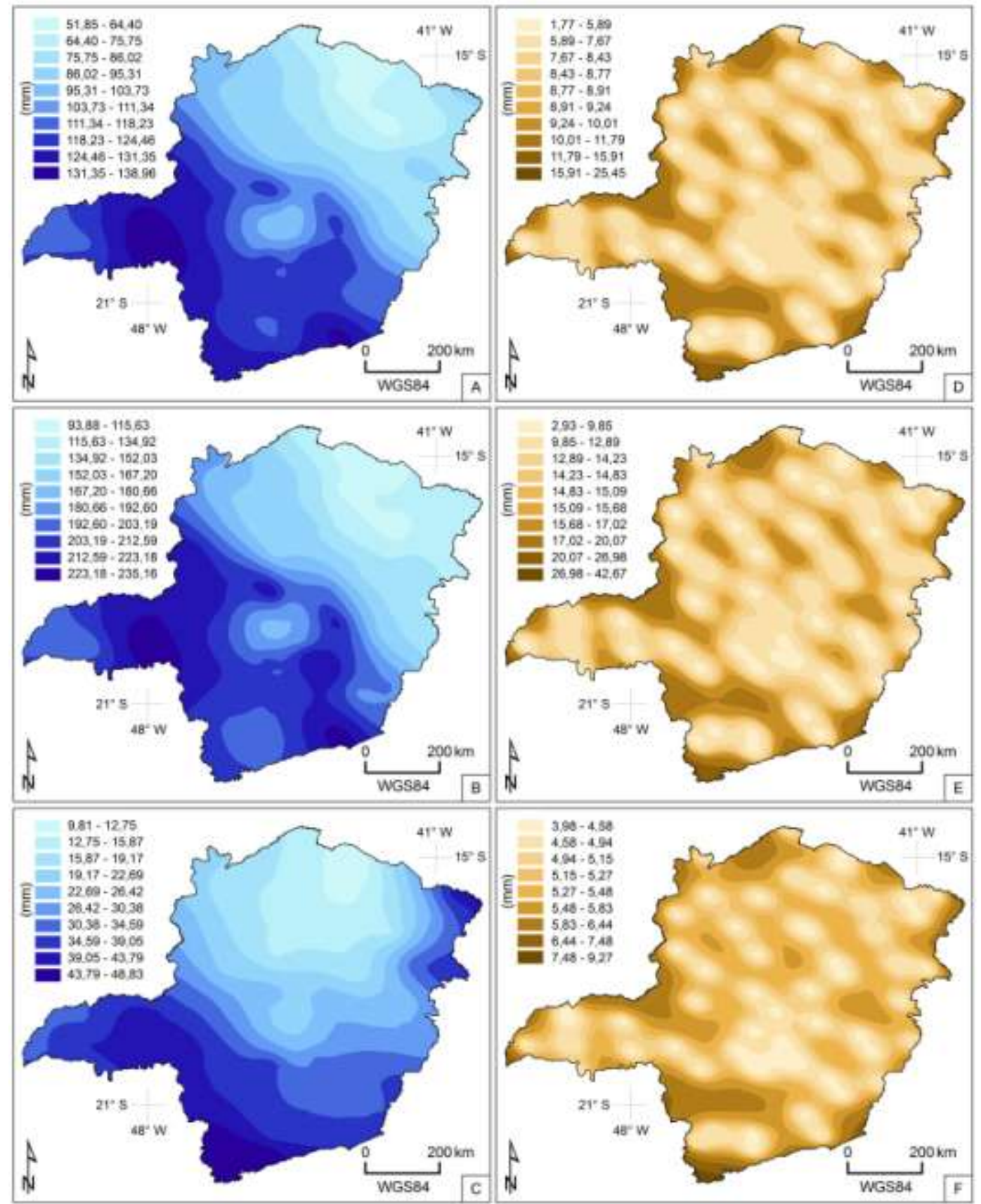

Figura 3: Estimativas da precipitação por krigagem ordinária para: (A) média anual, (B) média da estação chuvosa, e (C) média da estação seca, com as respectivas superfícies de erros de estimativa (D, E e F).

Em relação à cokrigagem (Figura 4), cabe destacar a melhora da estimativa para o período chuvoso, com a redução dos erros (Figura 4E). Na Figura 6 é mostrada a distribuição dos erros em relação ao tamanho da área de ocorrência, com um comportamento semelhante ao observado na krigagem. 

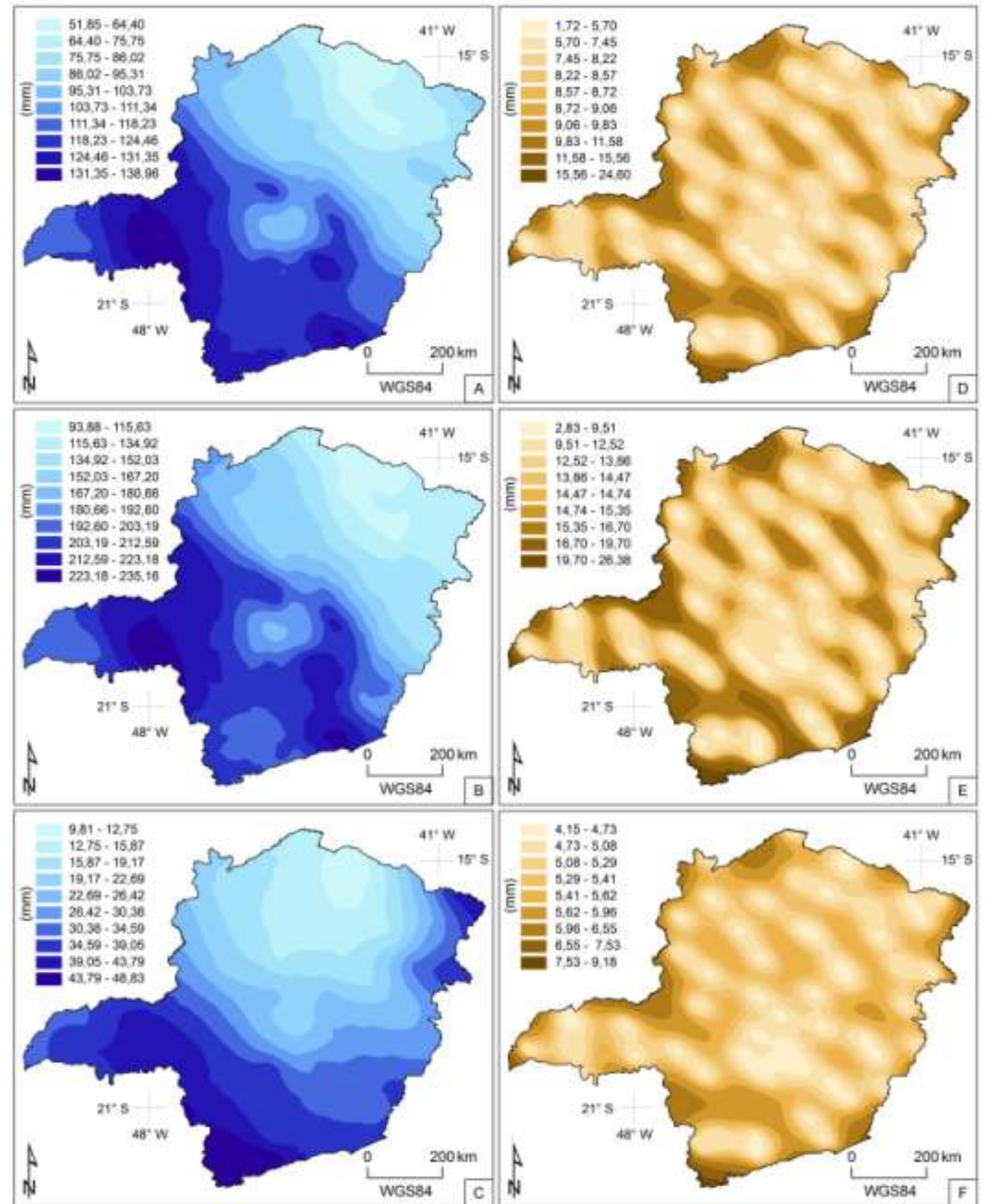

Figura 4: Estimativas da precipitação por cokrigagem ordinária para: (A) média anual, (B) média da estação chuvosa, e (C) média da estação seca, com as respectivas superfícies de erros de estimativa (D, E e F). 

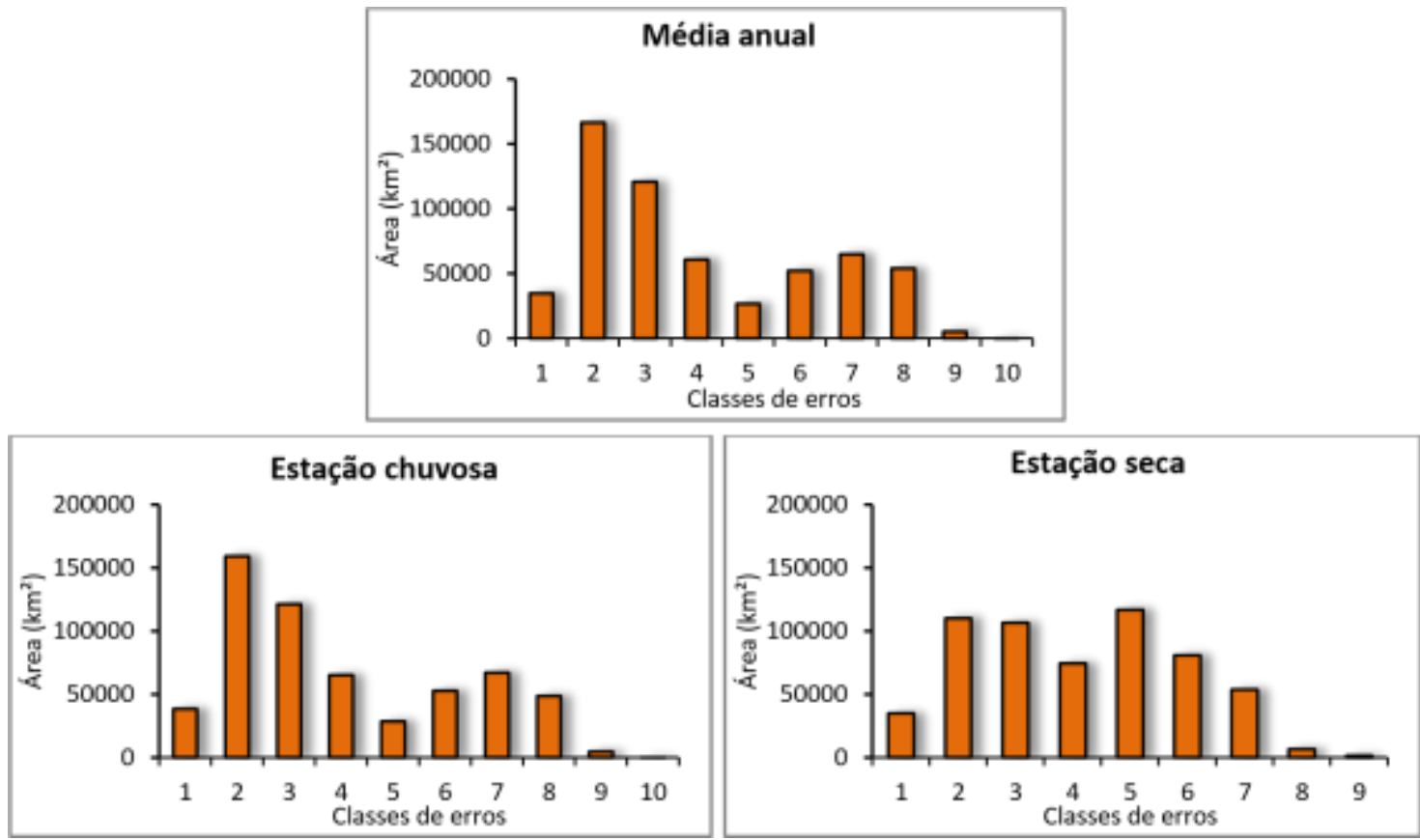

Figura 5: Distribuição dos erros de estimativas da precipitação por krigagem ordinária para a média anual, média estação chuvosa e média estação seca segundo a área.
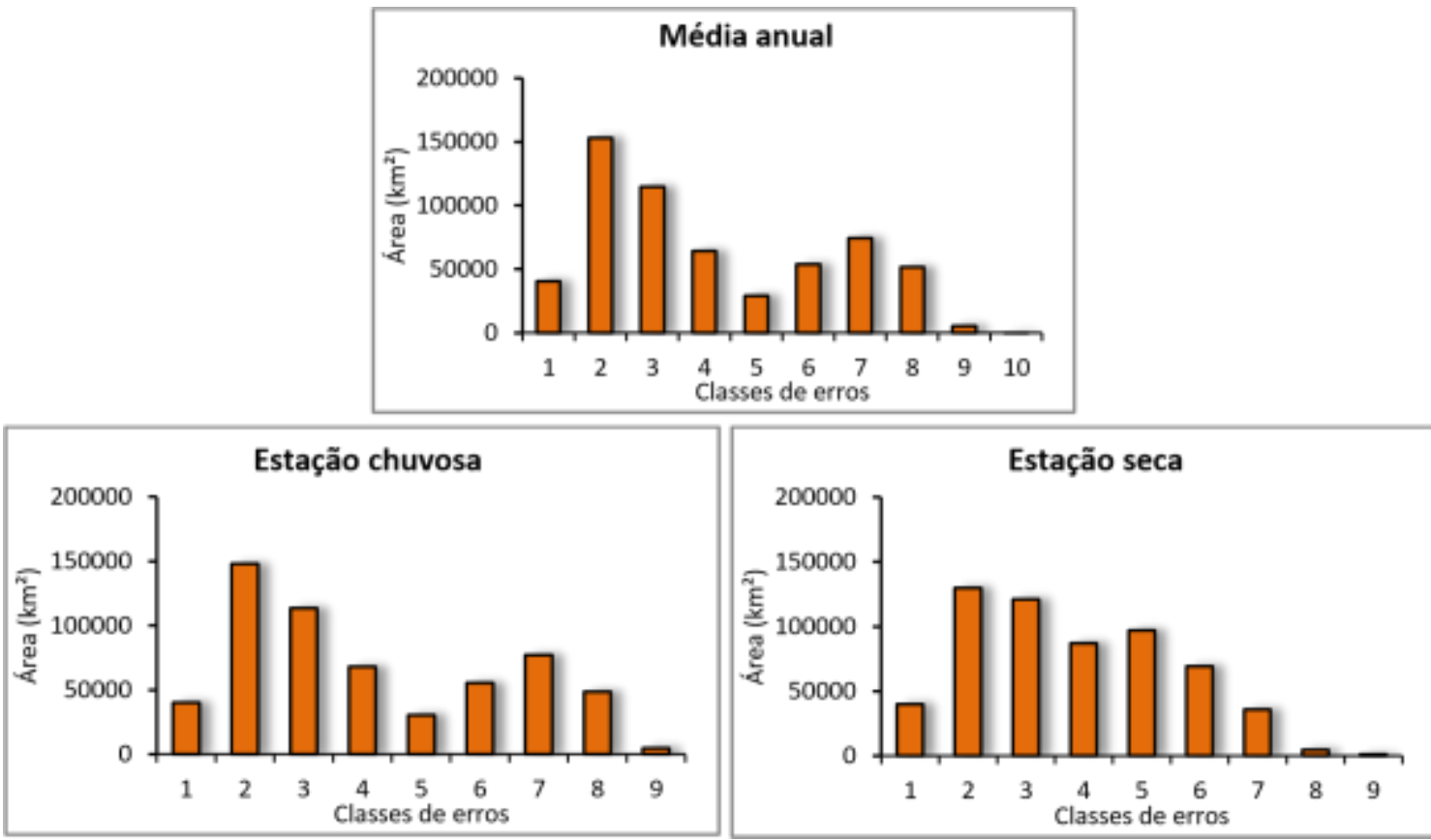

Figura 6: Distribuição dos erros de estimativas da precipitação por cokrigagem ordinária para a média anual, média estação chuvosa e média estação seca segundo a área.

\section{5- CONSIDERAÇÕES FINAIS}

A partir da aplicação da geoestatística, foi possível fazer as estimativas de superfícies de precipitação para os três períodos considerados na análise: média anual, média da estação chuvosa 
e média da estação seca. Com base nos resultados atingidos, podem-se fazer algumas considerações:

- em termos de estimativa de precipitação a krigagem ordinária ofereceu resultados satisfatórios;

- a altitude pode apresentar correlação mais forte com a precipitação na estação chuvosa;

- a geoestatística multivariada pelo método da cokrigagem pode ser útil para compreender melhor a distribuição da precipitação (variável primária) quando há uma correlação significativa dessa com a variável secundária, a exemplo da estação chuvosa.

A geoestatística seja pela krigagem ou cokrigagem oferece uma gama de análise não disponível nos métodos determinísticos, as quais permitem conhecer melhor a natureza dos dados e, assim, dar subsídios para uma estimação mais precisa da superfície de precipitação. Outro ponto positivo da geoestatística é a possibilidade do fornecimento da incerteza da estimativa, o que é útil para definir quais modelos oferecem melhores resultados.

Ressalta-se, contudo, a necessidade de um aprofundamento, tanto do método, como da variável, de forma a contribuir para a tomada de decisões ao longo de todo o processo de análise e definição de parâmetros.

\section{REFERÊNCIAS BIBLIOGRÁFICAS}

AGÊNCIA NACIONAL DE ÁGUAS - ANA. HidroWeb: Sistema de informações hidrológicas [online]. (Séries históricas disponíveis a partir de 2005). Disponível em: < http://hidroweb.ana.gov.br/default.asp>. Acesso em: 02 nov. 2005.

ANDRIOTTI, J. L. S. Fundamentos de estatística e geoestatística. São Leopoldo: Unisinos, 2003. $165 \mathrm{p}$.

ANDRIOTTI, J. L. S. Notas de geoestatística. Estudos tecnológicos - Acta Geologica Leopoldensia, São Leopoldo, v. 25, n.55, p. 3-14, 2002. Disponível em: <http://www.cprm. gov.br/publique/media/Art_Andriotti_notas_geoestatistica.pdf>. Acesso em: 15 nov. 2015.

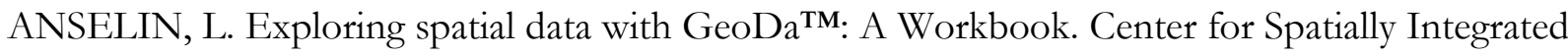
Social Science, Champaign - EUA: 2005. Disponível em: <http://www.csiss.org/ clearinghouse/GeoDa/geodaworkbook.pdf>. Acesso em: 10 nov. 2015.

CARVALHO, J. R. P. DE; ASSAD, E. D. Otimização de interpoladores espaciais para estimar chuva no Sistema Agritempo. Embrapa Informática Agropecuária, Campinas: 2003. Disponível 
em: <http://www.infoteca.cnptia.embrapa.br/infoteca/handle/doc/8851>. Acesso em: 08 nov. 2015.

CASTRO, L. M.; GIRONAS, J.; FERNANDEZ, B. Spatial estimation of daily precipitation in regions with complex relief and scarce data using terrain orientation. Journal of Hydrology, v. 517, p. 481-492, 2014. Disponível em: <http://dx.doi.org/10.1016/j.jhydrol.2014.05.064>. Acesso em: 07 nov. 2015

CUNHA, A. D. M.; LANI, J. L.; SANTOS, G. R. dos; FILHO, E. I. F.; TRINDADE, F. S.; SOUZA, E. Espacialização da precipitação pluvial por meio de krigagem e cokrigagem. Pesquisa Agropecuária Brasileira, Brasília, v. 48, n. 9, p. 1179-1191, 2013. Disponível em: $<$ http://www.scielo.br/scielo.php?script=sci_arttext\&pid=S0100-204X2013000900001\&lng= pt\&nrm=iso\&tlng=en>. Acesso em: 08 nov. 2015.

GANCHO, V. G. Noções de Estatística e Probabilidade. Ouro Preto: Universidade Federal de Ouro Preto, 2004.

GOOVAERTS, P. Geostatistical approaches for incorporating elevation into the spatial interpolation of rainfall. Journal of Hydrology, v. 228, n. 1-2, p. 113-129, 2000.

INSTITUTO NACIONAL DE METEOROLOGIA - INMET. Banco de dados meteorológicos para ensino e pesquisa [online]. Disponível em: <http://www.inmet.gov.br/portal/index.php?r =bdmep/bdmep $>$. Acesso em: 02 nov. 2015.

ISAAKS, E.H.; SRIVASTAVA, R.M. An introduction to applied geostatistics. New York: Oxford University, 1989. 561p.

JOHNSTON, K.; HOEF, J. M. V.; KRIVORUCHKO, K.; LUCAS, N. Using ArcGISTM Geostatistical Analyst. United States: ESRI, 2001.

MIRANDA, E. E. de; (Coord.). Brasil em Relevo. Campinas: Embrapa Monitoramento por Satélite, 2005. Disponível em: <http://www.relevobr.cnpm.embrapa.br>. Acesso em: 02 nov. 2015.

MOTA, V. C. Metodologia geoestatística para caracterizar a variabilidade temporal de elementos climáticos de Juiz de Fora - MG. 2008. Dissertação (Mestrado em Estatística e Experimentação Agropecuária) - Universidade Federal de Lavras - UFLA, Lavras, 2008.

NUNES, L. H.; VICENTE, A. K.; CANDIDO, D. H. Clima da região Sudeste do Brasil. In: CAVALCANTI, I. F. A.; FERREIRA, N. J.; SILVA, M. G. A. J. da; DIAS, M. A. F. da (Org.). Tempo e clima no Brasil. São Paulo: Oficina de Textos, 2009. 463 p.

SAADI, A. Ensaio sobre a morfotectônica de Minas Gerais (tensões intraplacas, descontinuidades crustais e morfogênese). 1991. Tese (Doutorado) - Universidade Federal de Minas Gerais, Belo Horizonte, 1991. 
YAMAMOTO, J. K.; LANDIM, P. M. B. Geoestatística: conceitos e aplicações. São Paulo: Oficina de Textos, 2013. 